\title{
ESTUdO DE MELHORIA DO “WHEEL GAP” SOBRE UM VEÍCULO EXISTENTE
}

\author{
Felipe Milak, Rafael Cruz \\ Renault do Brasil S.A. \\ E-mails: felipe.milak@renault.com, rafael.cruz@renault.com,
}

\section{RESUMO}

O design é um dos critérios mais apreciados pelos clientes e tem sido a cada dia mais decisivo no momento da compra de um automóvel. Tendo em conta a necessidade de se aprimorar este atributo, os construtores devem estar atentos a toda característica que impacte na sua aparência final. Uma delas é o que chamamos de "wheel-gap”, que define o vão entre as rodas e a carroceria. Esta característica cumpre um papel importante no design de um veículo, como sendo uma assinatura da marca para um veículo bem feito. Em um primeiro momento, podese imaginar que isto seja estritamente ligado ao design, que acompanhará o veículo até a sua substituição por um novo modelo e novo desenho. Porém, ao perceber que seu veículo já em produção deixa a desejar neste quesito, o construtor deve procurar alguma alternativa para melhorá-lo. Com este intuito, uma equipe de engenheiros e designers foi criada com objetivo de identificar soluções aplicáveis em curto prazo e com baixo custo. Este estudo exporá os critérios analisados sobre um veículo em produção e indicará a melhor solução para o construtor e seus clientes.

\section{INTRODUÇÃO}

O momento atual vivido pelo mercado automobilístico brasileiro se mostra como o mais competitivo já visto. Neste cenário os construtores automotivos se esforçam e buscam alternativas para surpreender seus clientes. É fato inegável que o design de um produto, em qualquer ramo em que esteja inserido, é um fator decisório para a sua venda. Isto fica ainda mais evidente quando o assunto é o automóvel, onde devido à vasta gama de opções e ofertas, o cliente tende a optar por aquele que lhe faça saltar aos olhos. Um exemplo concreto deste pensamento está expresso pelo volume de vendas atingido por um veículo dito por muitos, um "Premium" de entrada. Segundo dados da Fenabrave, no mês de abril de 2015 o veículo utilizado como benchmark foi o modelo mais vendido no mercado de varejo brasileiro. Segundo citação do gerente Milad Kalume Neto da consultoria automotiva Jato Dynamics à revista Exame [1], “o HB20 'chegou chegando' com um produto bem adequado, preço competitivo e design moderno”. Desta forma este veículo (modelo B) apresenta indícios de que um design bem acertado pode abrir o caminho para o sucesso de vendas no Brasil.

Por outro lado, o construtor que não estiver atendo a detalhes que impactem no design final de seus produtos, poderá perder significativo potencial de vendas. Este é o caso do Wheel Gap, uma característica por vezes despercebida, mas que tem uma contribuição fundamental na imagem de marca de um construtor. 


\section{INFORMAÇÕES GERAIS}

No presente estudo, será analisada a situação de um determinado modelo configurado com rodas de 15”, atualmente em produção no parque industrial brasileiro. Tal veículo foi originalmente concebido para atender especificamente a mercados emergentes, onde muitas vezes prevalece a busca pelo baixo custo de fabricação em detrimento de determinadas prestações, como o próprio design. Porém ao se deparar com um mercado em crescente competitividade e exigência como o brasileiro, surge a necessidade de se rever alguns critérios e adaptá-los.

\section{WHEEL GAP}

O "Wheel Gap" (Noir de Roue, em francês), é definido pelo vão existente entre a roda e o para-lama do veículo em ordem de marcha. Esta característica é um dos fundamentos do design automotivo, que na prática determina a harmonia entre a carroceria e a plataforma do veículo. Em um veículo onde este quesito tenha sido cuidadosamente trabalhado, é possível notar mesmo de forma inconsciente que se trata de um produto bem feito. Ao contrario, segundo o ponto de vista do design e da qualidade percebida, um vão muito pronunciado denuncia que algo de errado possa ter ocorrido ao longo do desenvolvimento do projeto.
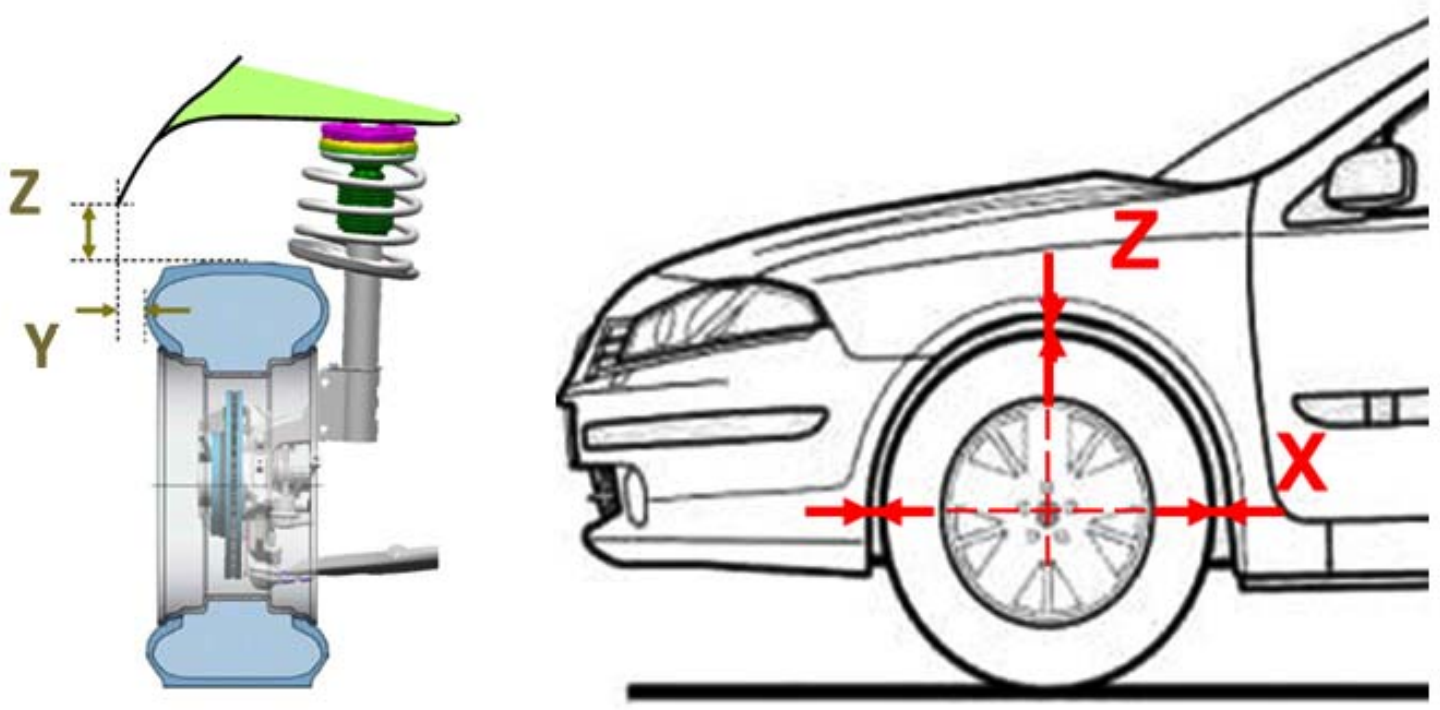

Figura 1 - Wheel-Gap.

Segundo Hugo Cristo [2], “design é uma síntese de variáveis contextuais por meio de processos analíticos”. Esta definição mostra o quão correlacionado está o aspecto visual de um veículo aos parâmetros objetivos e funcionais trazidos pela engenharia.

Objetivamente o wheel-gap é dado pela distancia em Z (altura) e Y (largura). Em fase de projeto, isto é determinado através da convergência entre o desenvolvimento da plataforma e o design da carroceria. Porém não apenas estas cotas em absoluto definem o aspecto do wheel-gap. É preciso estar atento também à harmonia das distancias das rodas com a carroceria em todo o contorno do pneu. Um exemplo visual desta característica pode ser dado observando-se um veículo que possui uma grande caixa de roda, porém com uma distancia reduzida entre o pneu e o para-lama. As rodas traseiras ficam mais próximas da carroceria em 
$\mathrm{Z}$, mas a distancia em X permanece inalterada, conferindo um aspecto de veículo carregado, mesmo estando vazio.

\section{EXPLORAÇÃO DO TEMA}

\subsection{Análise da Concorrência}

Os veículos analisados para este estudo foram selecionados de acordo com a sua gama e relevância quanto ao tema. Em seguida foi observado o volume de vendas de cada concorrente segundo dados da Fenabrave [3] (tabela I).

\begin{tabular}{|l|c|c|c|c|c|c|c|c|}
\cline { 2 - 10 } \multicolumn{1}{c|}{} & \multicolumn{2}{c|}{ Total } & \multicolumn{2}{c|}{ Varejo } & \multicolumn{3}{c|}{ Wheel Gap - \% Desvio / Veículo Estudo } \\
\cline { 2 - 10 } \multicolumn{1}{c|}{} & Vendas' & Ranking & Vendas & Ranking & D (Z) & T (Z) & D (Y) & T (Y) \\
\hline Veículo Estudo & 25.299 & $8^{\circ}$ & 15.242 & $14^{\circ}$ & DZ & TZ & DY & TY \\
\hline \hline Modelo A & 38.706 & $2^{\circ}$ & 34.543 & $1^{\circ}$ & $9 \%$ & $20 \%$ & $26 \%$ & $44 \%$ \\
\hline Modelo B & 33.337 & $3^{\circ}$ & 30.987 & $3^{\circ}$ & $34 \%$ & $39 \%$ & $59 \%$ & $65 \%$ \\
\hline Modelo C & 30.664 & $5^{\circ}$ & 19.600 & $8^{\circ}$ & $25 \%$ & $22 \%$ & $37 \%$ & $38 \%$ \\
\hline Modelo D & 29.345 & $7^{\circ}$ & 24.467 & $4^{\circ}$ & $11 \%$ & $3 \%$ & $70 \%$ & $41 \%$ \\
\hline Modelo E & 20.921 & $11^{\circ}$ & 17.840 & $9^{\circ}$ & $21 \%$ & $15 \%$ & $48 \%$ & $38 \%$ \\
\hline Modelo F & 5.807 & $33^{\circ}$ & 5.438 & $31^{\circ}$ & $28 \%$ & $32 \%$ & $26 \%$ & $44 \%$ \\
\hline
\end{tabular}

Tabela I - Concorrentes

Ao explorar as informações trazidas por estes veículos, é possível compreender que existe uma considerável distancia para o modelo objeto deste estudo. Para se aproximar da media do mercado neste contexto, se faz necessário reduzir as cotas Z e Y de cerca de $21 \%$ e $44 \%$ respectivamente. A figura 2 torna mais clara esta diferença.

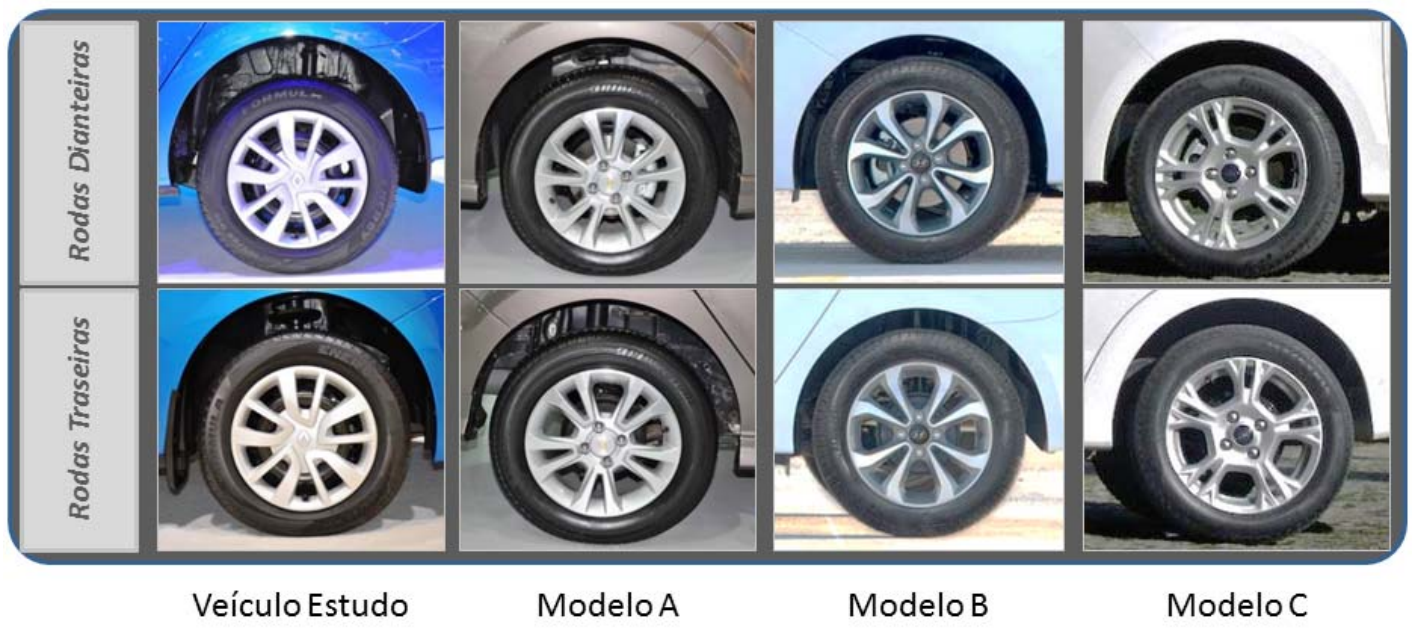

Figura 2 - Comparação Wheel-gap em Z

\subsection{Parâmetros de influencia}

Para inicio do estudo é necessário identificar os parâmetros que possam ter alguma influência nas cotas $\mathrm{Z}$ e $\mathrm{Y}$ e que eventualmente possam ser trabalhadas. O impacto 
que cada um deles imporia sobre a definição técnica do veículo será de fundamental importância para a escolha da melhor solução.

Considerando o jogo em Z, os parâmetros mais relevantes a serem analisados são:

1/ Altura da carroceria - contribuição direta na distancia do para-lama com as rodas 2/ Diâmetro externo do conjunto roda/pneu - mantendo-se o ponto do centro da roda em relação ao referencial veículo, o aumento do diâmetro de rodagem contribui diretamente na redução do jogo em Z.

3/ Design dos Para-lamas - deve ser determinado de forma a comportar toda a gama de tamanhos de rodas previsto para o veículo. Tem-se o wheel-gap mais apropriado ao mesmo tempo em que não há diversidade no diâmetro externo das rodas.

4/ Design dos Para-choques - consequência do design dos para-lamas, tem seu papel importante para preservar a regularidade do jogo com a roda ao longo do arco de roda - cota em X.

Em relação ao jogo em Y, é possível trabalhar sobre os parâmetros abaixo:

1/ Arquitetura de Trens Dianteiro e Traseiro - a posição lateral das rodas é consequência da bitola de trem, determinada para o veículo. Esta característica esta vinculada a uma serie de outros parâmetros que definem o comportamento da suspensão e consequentemente do veículo.

2/ Offset das Rodas - atua diretamente na cota $\mathrm{Y}$ ao determinar lateralmente a posição do centro da roda em relação ao veículo.

3/ Largura das Rodas - papel direto no preenchimento da caixa de roda. É possível exteriorizar as rodas com o simples aumento da sua largura, mantendo-se a posição do seu centro.

4/ Design dos Para-Lamas - da mesma forma que para a cota Z, o desenho da carroceria é determinante para o aspecto do wheel-gap em Y.
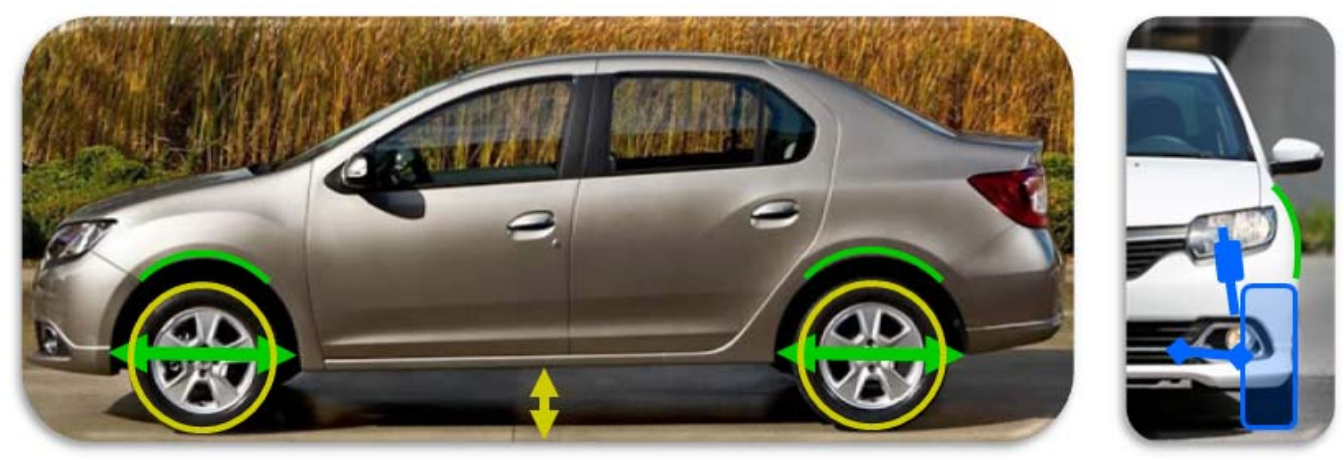

Figura 3 - Parâmetros influentes no wheel-gap

\subsection{Análise de impactos na definição técnica do veículo}

Considerando as alternativas identificadas no item anterior, é possível determinar de imediato, aqueles que não poderão ser levados em conta. Os critérios principais para exclusão estão ligados especialmente à viabilidade econômica, ao prazo estimado para aplicação e à degradação de alguma funcionalidade do veículo. Desta forma, 
optou-se por não trabalhar sobre os parâmetros: design de carroceria, diâmetro externo das rodas e largura das rodas.

Não é de praxe considerar alterações de linhas de design de carroceria na região lateral para um eventual face-lift de um modelo em série. O motivo principal desta decisão é o numero elevado de peças de carroceria envolvidas, tornando o custo impeditivo frente ao potencial impacto visual. Assim, no caso do estudo de melhoria do wheel-gap, seria necessário modificar peças de grande porte como as Laterais da Carroceria.

Um possível estudo do aumento do diâmetro das rodas também não será considerado por se tratar de uma característica imposta ao veículo objeto de estudo - rodas de 15”.

Frente a estas considerações iniciais, parte-se para a análise dos parâmetros que poderiam se tornar escopo de uma próxima versão do veículo. Para a melhoria da cota Z, a única alternativa viável que resta é a redução da altura da carroceria.

No que se refere à cota $Y$, existem ainda dois parâmetros que serão objeto de estudo. Estes possuem o mesmo objetivo de exteriorizar as rodas em relação à carroceria. $\mathrm{O}$ primeiro impacta unicamente a definição técnica das rodas. A alteração do Offset distância do plano de interface da roda com o cubo e o plano meridiano do centro da roda - permite que o plano externo da roda fique posicionado mais próximo a extremidade da carroceria. A outra opção, mais complexa, propõe uma alteração de parâmetros de configuração de suspensões dianteira e traseira, para chegar a este resultado. A ideia neste caso seria manter a definição das rodas, trabalhando sobre o posicionamento da ponta de eixo. Para ambos os casos, deve-se ter atenção sobre eventuais efeitos colaterais sobre as características funcionais das suspensões.

\subsection{Legislação}

Como ocorre com a maioria dos veículos, a sua comercialização não está restrita a um único mercado. Quando o desenvolvimento de um veículo é iniciado, o construtor já deve ter bem definido os países e legislações às quais este novo produto deverá responder. Um automóvel vendido no Brasil, por exemplo, pode ser, e normalmente é, o mesmo que aquele vendido em outros países. Naturalmente, existem diferenças ligadas às exigências dos clientes que também são diversificadas, mas que impactam, na grande maioria, em escolha de equipamentos e nível de prestações já existentes no veículo. Porém quando falamos do DNA do veículo, traduzido por suas grandes cotas, dimensões, bem como por seu design, não há margem para grandes mudanças.

Neste sentido, há algumas características que acompanharão o veículo por onde quer que ele seja comercializado. É o caso do wheel-gap que em base é definido por suas características de design e plataforma. Existe ainda um agravante para esta característica quando este mesmo veículo é destinado tanto a países desenvolvidos quanto a subdesenvolvidos. Nestes dois cenários, as condições de rodagem são distintas, sendo para este necessário o aumento da distancia do veículo em relação ao solo. Esta necessidade se traduz de forma direta e contrária ao aspecto de wheel-gap do veículo. 
Por se tratar de um estudo sobre um veículo europeu, primeiramente foram identificadas algumas normas europeias ligadas à altura de carroceria e posição das rodas em relação à carroceria. Em seguida procurou-se identificar a correlação destas normas com a legislação brasileira. Os temas principais identificados foram: aplicação de corrente nas rodas e recobrimento das rodas pela carroceria. Não há restrições ligadas a altura mínima da carroceria em relação ao solo. Neste caso o construtor pode aplicar seus próprios critérios.

\subsubsection{Aplicação de correntes}

Utilizada para condições extremas de rodagem sobre a neve, este equipamento é largamente utilizado em países europeus. Em grande parte deles, o uso se faz obrigatório sobre ao menos duas rodas motrizes, quando em regiões de montanhas frequentemente sujeitas a neve.

Esta condição de obrigatoriedade faz com que o construtor guarde uma margem de espaço na caixa de roda para permitir o uso de correntes. No caso do Brasil, não há exigências regulamentares quanto a este uso assim como nos demais países da América. Portanto neste cenário, a adaptabilidade do veículo a esta utilização é entendida como uma prestação suplementar do veículo.

No que impacta o estudo de melhoria do wheel-gap, o fato de não haver obrigatoriedade pela utilização de correntes nos pneus se coloca como uma restrição a menos no volume de funcionamento ocupado pelas rodas. Desta forma abre-se a possibilidade de desloca-las conforme a necessidade.

\subsubsection{Recobrimento das rodas pela carroceria}

A Comunidade Europeia (UCE) exige que seus veículos atendam a uma característica chamada de recobrimento das rodas ou "wheel-guard". Esta norma [4] determina que as rodas em linha reta devam estar cobertas por algum elemento de carroceria em uma faixa que cobre de $30^{\circ}$ a $-50^{\circ}$ em relação ao eixo vertical passando pelo centro da roda. Esta exigência está ilustrada na figura 4. 


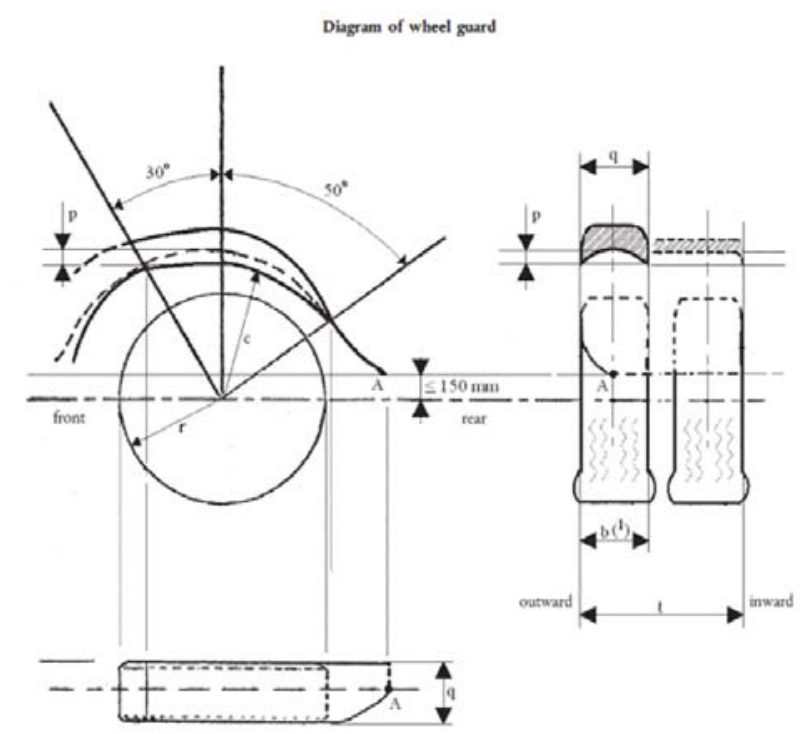

Figura 4 - Commission Regulation (EU) No 1009/2010

Já nos países da América de maneira geral, a legislação se coloca de maneira menos restritiva. No Brasil, mais precisamente, a única determinação é regida pelo artigo $8^{\circ}$ da Resolução do Contran $N^{\circ} 292$ de 29 de agosto de 2008 [4], que restringe a utilização de rodas e pneus que ultrapassem os limites externos dos para-lamas do veículo.

Art. $8^{\circ}$ Ficam proibidas:
I - A utilização de rodas/pneus que ultrapassem os limites externos dos pára-lamas do
veículo;

Figura 5 - Resolução Contran N²92

\section{ESTUDO DE POTENCIAL}

4.1. Análise de arquitetura veicular

Um ponto fundamental para um estudo mais detalhado é a analise da arquitetura de plataforma do veículo. Isto resultará na determinação do potencial de ganho permitido para este veículo, considerando o envelope no qual foram construídos seus sistemas. Para este estudo são considerados os seguintes elementos: envelopes de roda, aplicação de correntes sobre os pneus, recobrimento de rodas e definição dos para-lamas.

\subsubsection{Analise do envelope de roda dianteiro}

O envelope de roda dianteiro é a representação em um único volume de todas as posições possíveis para o conjunto roda-pneu de acordo com a cinemática das suspensões. Estas posições variam conforme a condição de esterçamento da direção - máximo externo e máximo interno - e a posição vertical da suspensão - de rebound até batente. Além disso, o EDR também considera a 
característica elástica da suspensão (eventual deformação de suas juntas e articulações em condições de esforços).

A avaliação deste elemento é essencial, uma vez que representa uma delimitação imposta pela engenharia ao setor de design, para a realização do desenho do para-lama. Por vezes, este limite não é aproveitado, devido a restrições intrínsecas ao desenvolvimento do design do veículo. Como resultado, acaba-se por obter uma cota Y do wheel-gap superior a desejada.

Ao se avaliar este critério sobre o veículo em estudo, adota-se a condição de que não é permitido haver contato entre o envelope de roda (EDR) e o paralama. Desta forma, de um ponto de vista mais prático, pode-se estimar o potencial de ganho em Y através da distancia neste eixo de coordenadas entre o envelope de roda e o para-lama. Para o veículo em estudo, observou-se um potencial de ganho de $44 \%$ neste aspecto (figura 4 ).

Em relação ao critério de recobrimento das rodas pelos para-lamas, a legislação europeia indica que o veículo esteja em ordem de marcha com dois ocupantes. Para a legislação brasileira, não há especificação quanto à condição de carga do veículo, portanto para esta analise foi adotado o mesmo critério europeu. Neste caso, deve-se verificar a distancia entre o plano externo do pneu e o ponto mais externo da carroceria (normalmente coincide com o eixo vertical passante pelo centro da roda). Um jogo residual de $5 \mathrm{~mm}$ deve ser mantido para garantir o respeito a esta exigência, mesmo havendo dispersões geométricas do sistema de suspensão, determinantes para a posição lateral das rodas. $\mathrm{O}$ ganho potencial permitido para este critério é de cerca de $64 \%$.

Há de se notar, todavia, que ao se modificar a posição Y do centro da roda, se faz necessária a reconstrução do EdR, para verificação da nova configuração. A exteriorização das rodas impacta neste volume como um todo e não somente na coordenada Y.

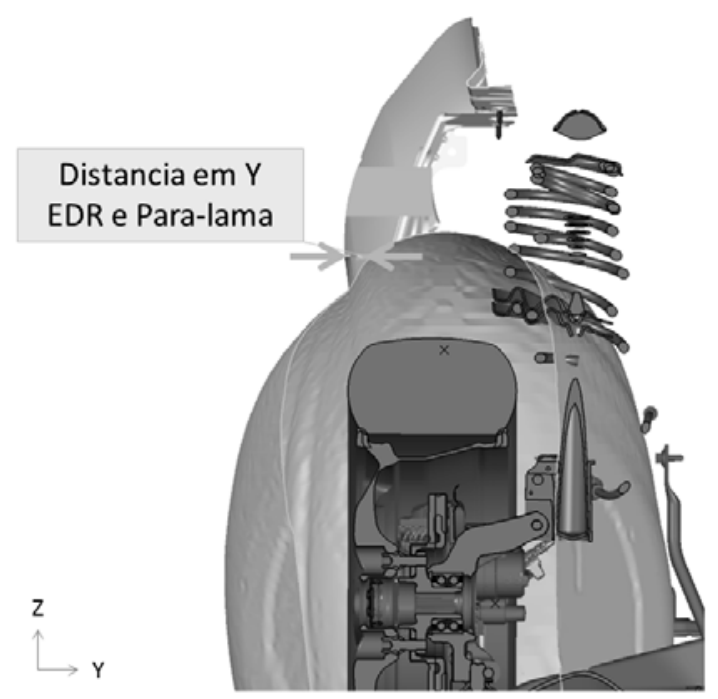

Figura 6 - Distância em Y entre EDR e Para-lama 
Para a cota Z observa-se da mesma forma as distancias nesta coordenada do EdR em relação ao seu entorno. Desta forma é determinado o elemento adjacente mais próximo que se colocará como limite para o deslocamento vertical das rodas dianteiras. No caso do veículo em estudo, observa-se que a situação de jogo existente já é limite em relação ao Protetor da Caixa de Roda. Esta situação impossibilita que seja alterada a posição de batente do eixo dianteiro. Por consequência, ao se reduzir a altura do veículo vazio ao mesmo tempo em que se mantem a posição de batente, tem-se uma redução do curso útil da suspensão (veículo vazio-batente). Sendo assim, admitindo-se a mesma posição de batente, a parte superior do EdR se manterá inalterada para qualquer nova altura do veículo em ordem de marcha (figura 7).

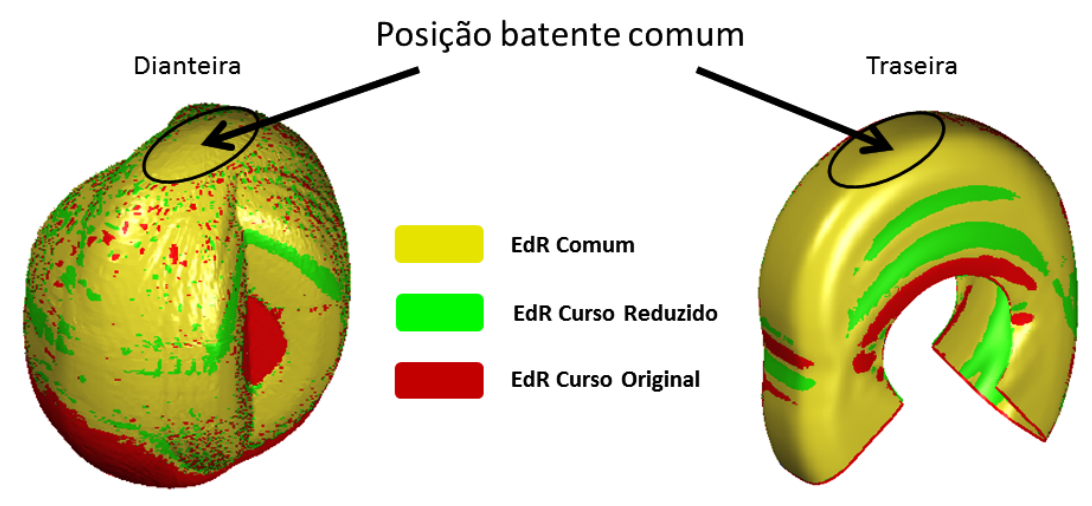

Figura 7 - EdR Curso Reduzido Vs. Original

Em conclusão, do ponto de vista da arquitetura veicular para o veículo em estudo existe um potencial de ganho em Y de cerca de 44\%. Com esta melhoria, o veículo se posicionaria dentro da média de seus concorrentes. Em relação ao Z, existe o potencial para chegar a media da concorrência, com redução de $22 \%$.

\subsubsection{Analise do envelope de roda traseiro}

Da mesma forma como descrito para o dianteiro, o EDR traseiro também representa o volume criado pelas posições possíveis para a roda traseira, considerando a cinemática da suspensão. A única diferença existente é a ausência de esterçamento das rodas, o que resulta em um volume lateral menor.

A forma de análise também se assemelha à da parte dianteira, sendo interditada qualquer situação de contato deste EDR com a carroceria. Assim, para a cota Y encontra-se o potencial de ganho ao se encontrar a distancia entre o EDR e o elemento adjacente mais próximo. O critério de recobrimento das rodas traseiras também deve ser verificado. Diferentemente da suspensão dianteira (pseudo MacPherson), para a suspensão traseira (eixo de torção) uma eventual exteriorização da roda em Y não impõe variação importante em outros eixos de coordenadas, devido à diferença de característica cinemática entre ambas. Para o veículo estudado, o elemento limitante é a Coluna " $C$ " da carroceria. Foi verificado que atualmente, esta condição já é limite e ao se deslocar a roda para 
o exterior da carroceria, logo seria observado o contato com a mesma. Desta forma, não haveria possibilidade imediata de deslocamento do EDR para fora (figura 8).

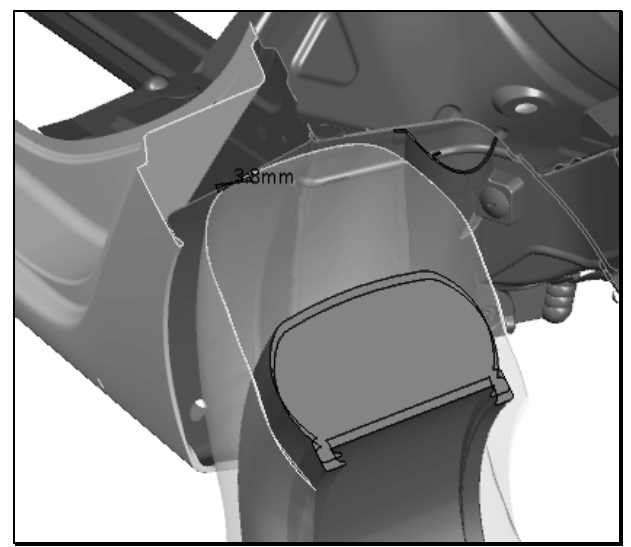

Figura 8 - Proximidade entre EdR e Coluna C

Para solucionar esta questão observou-se que seria necessário afastar o EDR desta região de proximidade. Para tanto, dentre outras soluções, determinou-se que o mais viável seria reduzir a posição de batente da suspensão traseira de cerca de 5\% em relação ao curso útil total da suspensão. Como consequência, tem-se a redução do volume do EDR em seu limite superior/frontal (devido à característica de deslocamento do eixo de torção). Esta modificação seria suficiente para permitir o deslocamento das rodas traseiras e consequentemente obter o ganho em $\mathrm{Y}$ do wheel-gap no mesmo valor absoluto que nas rodas dianteiras.

No que se refere ao recobrimento, observa-se que as rodas traseiras estão mais interiorizadas que as da frente, com potencial de ganho de $\mathrm{Y}$ maior do que no eixo traseiro.

\subsubsection{Analise da distancia ao solo}

Observou-se também que a altura atual do para-choque dianteiro em relação ao solo está limite. Portanto se faz necessária a modificação deste elemento caso se opte por reduzir a altura do veículo.

\subsubsection{Síntese do potencial de ganho}

Em conclusão do estudo de arquitetura entorno das rodas, vê-se maior restrição ao deslocamento das rodas em Y sobre o eixo dianteiro. Desta forma esta restrição acaba sendo limitante também para o eixo traseiro, uma vez que se decidiu trabalhar sobre o offset das rodas. No caso do ganho em Z, não existe restrição em termos de espaço, considerando a hipótese de manutenção ou redução da posição de batente das suspensões dianteiras e traseiras. Claramente esta condição imporia uma redução do curso útil das suspensões (entre as posições de veículo carregado até o batente) a ser estudado mais adiante. 
Na tabela abaixo se tem uma síntese do que seria possível realizar em se trabalhando sobre a altura do veículo (Z) e também no offset das rodas (Y).

\begin{tabular}{|c|c|c|c|}
\hline \multicolumn{4}{|c|}{ Potencial Ganho / Wheel-gap atual } \\
\hline Eixo & Critério & $\mathrm{Z}^{*}$ & $\mathrm{Y}$ \\
\hline \multirow{2}{*}{ Dianteiro } & EDR & $100 \%$ & $\mathbf{4 4 \%}$ \\
\cline { 2 - 4 } & Recobrimento & - & $64 \%$ \\
\hline Traseiro & EDR Dianteiro & $100 \%$ & $\mathbf{2 9 \%}$ \\
\hline
\end{tabular}

* Para uma posição igual ou inferior dos batentes de suspensão

Tabela II - Síntese do potencial de ganho

\section{ESTUDO DE SOLUÇÃO TÉCNICA}

Tendo como base o estudo técnico preliminar e da analise de arquitetura de plataforma, é possível estudar as soluções técnicas e seus possíveis impactos no veículo como um todo. As possibilidades consideradas para melhoria do wheel-gap em $\mathrm{Z}$ e $\mathrm{Y}$ foram respectivamente a redução da altura da carroceria e a redução do offset das rodas. $\mathrm{O}$ estudo a seguir tem o objetivo de identificar os impactos de cada modificação na definição do veículo. Por se tratar de um veículo existente em produção é fundamental que se proponham soluções com baixo custo e tempo de aplicação.

\subsection{Melhoria da cota Z}

Para obter o máximo ganho em Z, é necessário compreender alguns critérios que definem a altura do veículo. Primeiramente, é importante lembrar que o wheel-gap é observado com o veículo em ordem de marcha (vazio, com reservatórios preenchidos). Sendo assim, é sobre esta configuração do veículo, onde será necessário trabalhar.

Um fator importante nesta análise é a altura do veículo em condição de carga máxima. Esta representa a mínima distancia do veículo em relação ao solo e define a sua capacidade de atravessar obstáculos. Em um país que tradicionalmente possui degradada condição em suas estradas, este fator é de extrema relevância.

Um terceiro item a ser considerado, é a definição do batente da suspensão. Este delimita o fim de curso da suspensão e por consequência a posição das rodas em relação à carroceria. Como foi verificado anteriormente, para o veículo em estudo, admitiu-se que a posição de batente deveria ser mantida, uma vez que sua modificação acarretaria em uma evolução na parte superior do Envelope de Roda, gerando grande impacto sobre a definição do veículo.

Deste ponto, entende-se que é necessário reduzir a altura do veículo vazio preservando sua capacidade mínima de atravessamento de obstáculos (veículo carregado). Para satisfazer a todos estes requisitos, outro fator entraria em jogo. Ao se realizar esta proposta, diminuir-se-ia o curso vazio-carregado da suspensão. Então, para uma mesma massa em questão, esta redução de curso deve ser realizada por meio do aumento da rigidez das molas. Porém, ao se alterar esta característica, temse um aumento direto na frequência própria de oscilação da suspensão, trazendo sensível degradação da prestação de conforto do veículo a seus ocupantes. Outro 
inconveniente desta hipótese seria a maior necessidade de ensaios de validação e o potencial risco de impactos adicionais sobre a carroceria, devido ao aumento dos esforços mecânicos sobre a mesma. Portanto, se mostraria inviável em custo, prazo e qualidade.

Desta forma, decidiu-se por privilegiar o conforto em detrimento da capacidade de atravessamento de obstáculos. Esta decisão abriu caminho para se avaliar a possibilidade de se reconduzir uma solução já existente sobre os modelos comercializados na Europa. Esta solução responderia a estes requisitos, por apresentar o mesmo curso das suspensões e posição dos batentes, apesar de ter as alturas em ordem de marcha e carregado cerca de $6 \%$ mais baixos. Da mesma forma, haveria facilidade de validações e verificações de outros sistemas e funções dependentes da altura do veículo.

Portanto, a aplicação desta solução permite um ganho em Z no wheel-gap de 16\% na dianteira e de $10 \%$ na traseira.

\subsubsection{Impactos na definição técnica}

Para entregar ao veículo sua nova configuração, identificam-se os impactos na sua definição técnica. Em outras palavras, quais elementos e sistemas estariam sendo modificados. Para reduzir a altura em 6\% na suspensão dianteira, devese modificar a posição dos apoios inferiores das molas sobre os amortecedores dianteiros. Desta maneira, preserva-se a mesma definição das molas dianteiras para qualquer definição de altura deste modelo.

Esta modificação demandaria um investimento sobre o ferramental do amortecedor. Além da modificação seria necessário um ensaio de calibração da curva de amortecimento do amortecedor. Para a suspensão traseira, a redução de altura se faz sobre as molas. O parâmetro a ser modificado na definição é a sua altura livre.

\subsection{Melhoria da cota $Y$}

Como visto anteriormente, a forma mais rápida e objetiva de se reduzir a cota Y é trabalhando-se sobre o offset da roda. Inicialmente, tomou-se como base o ganho máximo possível para a exteriorização das rodas dianteiras, que finalmente se mostrou o fator limitante. $\mathrm{O}$ estudo de deslocamento em $\mathrm{Y}$ da roda de um veículo requer uma analise criteriosa sobre os possíveis impactos nos parâmetros construtivos da suspensão dianteira.

Ao se exteriorizar o conjunto roda pneus em relação à carroceria, tem-se uma consequência imediata sobre o sistema de suspensão. Os esforços atuantes sobre a suspensão crescem proporcionalmente ao aumento do momento (distancia entre o centro da roda e a articulação da suspensão). Isto exigira eventualmente que sejam realizados cálculos de resistência mecânica da suspensão para confirmar o correto dimensionamento do sistema. 
Outro fator importante presente sobre suspensão dianteira é o deslocamento do pino mestre que é diretamente afetado ao se deslocar lateralmente o centro da roda. Esta característica, definida por Robert Bosch [6] na figura 9, é a distancia do ponto médio de contato da roda com a superfície da pista e o ponto de interseção do eixo do pino mestre com a superfície da pista. Este parâmetro determina a influência das forças interferentes, como as de aceleração e desaceleração, sobre o sistema de direção. Quando o ponto de interseção do eixo do pino mestre está posicionado entre o ponto médio de contato do pneu com o solo e a lateral externa do veículo, o deslocamento é negativo. Tenta-se normalmente atingir deslocamento nulo ou negativo para se minimizar estes efeitos.

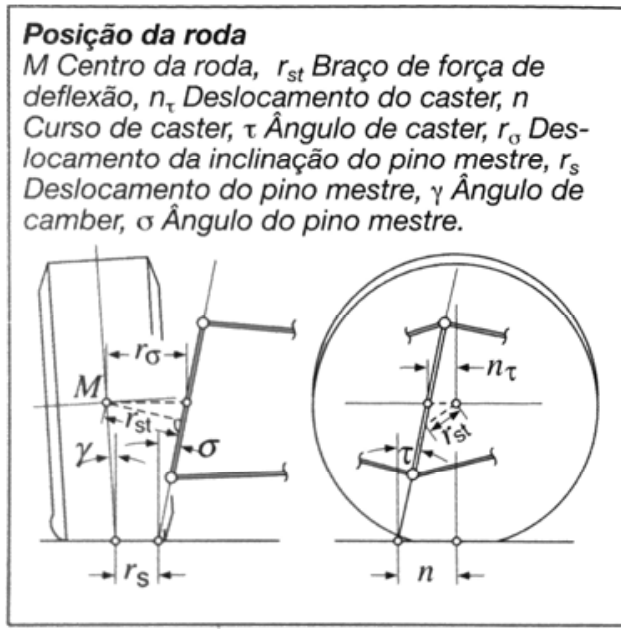

Figura 9 - Deslocamento do pino mestre.

No caso deste estudo, a melhoria da cota Y do wheel gap depende da exteriorização da roda em relação a carroceria. Em outras palavras, para este fim é necessário penalizar o deslocamento do pino mestre, tornando-o mais positivo. Assim, este fato representa uma limitação importante, uma vez que o comportamento dinâmico do sistema de direção pode se tornar mais instável.

Para atingir o máximo de ganho em Y, seria necessário reduzir o offset das rodas de 25\%. Porém, atingir esta meta traria finalmente estas consequências indesejadas, como o desvio da direção em aceleração. Tendo como base o histórico do projeto, determinou-se um limite aceitável para a redução do offset de $8 \%$.

Seria possível imaginar outra solução para exteriorizar as rodas, como o deslocamento do conjunto da ponta de eixo como um todo, de modo a exteriorizar as rodas ao mesmo tempo em que se melhoraria o deslocamento do pino mestre. Porém esta solução demandaria praticamente a reconstrução completa da suspensão, impondo a modificação de braços inferiores, berço do motor, braços de direção, barra estabilizadora, entre outros. Desta forma, esta hipótese é considerada inviável para as pretensões do presente estudo.

Em relação ao eixo traseiro, conforme analise anterior, é necessária para qualquer deslocamento exterior da roda, uma redução da posição de batente da suspensão. A proposta é de uma redução de $8 \%$ no curso da suspensão (veículo carregado até o 
batente). Esta redução impõe um reforço da estrutura do eixo traseiro, uma vez que se aumentarão os esforços sobre o mesmo. Isto se deve ao aumento da frequência em que se atingirá o batente da suspensão. Para esta hipótese, é necessário modificar o apoio do batente do amortecedor traseiro.

Em termos funcionais, a alternativa mais coerente com a proposta do estudo é a redução de $8 \%$ na dimensão do offset das rodas. Esta mudança se traduz em uma melhoria de $13 \%$ do wheel-gap em Y para as rodas dianteiras e de $9 \%$ para as rodas traseiras.

\subsubsection{Impactos na definição técnica}

Em termos de projeto, a aplicação da solução de redução do offset impõe o desenvolvimento de novas rodas, tanto em aço quanto em alumínio. Em paralelo, para permitir este deslocamento lateral no eixo traseiro, foi identificada a necessidade de modificação do apoio do batente do amortecedor traseiro. Por consequência, haverá uma redução do curso da suspensão e o aumento da incidência de esforços que deverão ocorrer sobre o eixo. Por fim, haveria a necessidade de reforçar o eixo traseiro.

\subsubsection{Síntese da solução}

O quadro abaixo demonstra um resumo dos impactos principais para a aplicação da solução de melhoria do wheel-gap para um projeto de face-lift do veículo em estudo.

\begin{tabular}{|c|c|c|c|c|c|}
\hline & & \multicolumn{2}{|c|}{ Melhoria Wheel-Gap } & \multicolumn{2}{|c|}{$\begin{array}{l}\text { Solução Wheel-Gap - Horizonte de aplicação: } \\
\text { Face-lift }\end{array}$} \\
\hline & Solução & Possível & Desejada & Peça & Status \\
\hline \multirow{5}{*}{2} & \multirow{5}{*}{$\begin{array}{l}\text { - } 8 \% \text { Altura Dianteira } \\
\text { - 4\% Altura Traseira }\end{array}$} & \multirow{5}{*}{$\begin{array}{c}16 \% \text { Dianteira } \\
13 \% \text { Traseira }\end{array}$} & \multirow{5}{*}{$\begin{array}{l}\text { 21\% Dianteira } \\
\text { 22\% Traseira }\end{array}$} & Para-Choque Dianteiro & Novo \\
\hline & & & & Defletor Aerodinamico & Modif \\
\hline & & & & Amortecedor Dianteiro & Modif \\
\hline & & & & Molas Traseiras & Novo \\
\hline & & & & Protetor Carter Plastico & CO \\
\hline \multirow{4}{*}{$\mathbf{Y}$} & \multirow{4}{*}{$\begin{array}{c}\text { - } 8 \% \text { Offset Rodas } \\
-8 \% \text { Batente Traseiro }\end{array}$} & \multirow{4}{*}{$\begin{array}{c}\text { 13\% Dianteira } \\
\text { 9\% Traseira }\end{array}$} & \multirow{4}{*}{$\begin{array}{l}\text { 44\% Dianteira } \\
\text { 45\% Traseira }\end{array}$} & Amortecedor Traseiro & Modif \\
\hline & & & & Eixo Traseiro & $\mathrm{CO}$ \\
\hline & & & & Rodas de Alumínio 15" & Novo \\
\hline & & & & Rodas de Aço 15" & Novo \\
\hline
\end{tabular}

Tabela III - Síntese do Estudo

\section{CONCLUSÃO}

Analisando-se o resultado alcançado com o presente estudo, é possível concluir que o objetivo de igualar a característica do wheel-gap em relação à média do mercado não foi alcançada. As soluções propostas, que atendiam aos principais requisitos de custo e prazo pré-estabelecidos no projeto, foram suficientes para atingir $67 \%$ do objetivo de melhoria da cota $\mathrm{Z}$ e $25 \%$ para a cota Y. 
Estes resultados nos revelam a dificuldade de se alterar uma característica de design sobre um veículo existente. Da mesma forma, o trabalho permitiu reforçar a importância da sinergia entre os profissionais do design e da Engenharia na busca de soluções técnicas que visam proporcionar para o cliente final, veículos mais atrativos.

\section{REFERÊNCIAS}

[1] YAZBEK, Priscila. Os carros preferidos no Brasil por faixa de motorização.

Disponível em http://exame.abril.com.br/seu-dinheiro/noticias/os-carros-preferidos-no-brasilpor-faixa-de-motorizacao.

Acesso em: 25/05/2015

[2] SANT’ANA, Hugo Cristo. Design sem designer. Serra: Edição do Autor, 2013. P.20

[3] FENABRAVE. Informativo - Emplacamentos. Ed.148. São Paulo, 01 de Maio de 2015. Disponível em

http://www3.fenabrave.org.br:8082/plus/modulos/listas/?tac=download\&file=/listas/plusfiles/ 4_2015_04_2.pdf

[4] COMMISSION REGULATION (EU). Official Journal of the European Union $\mathbf{N}^{\circ}$ 1009/2010. UE, 09 de Novembro de 2010. Disponível em http://eur-lex.europa.eu/legalcontent/EN/TXT/HTML/?uri=CELEX:32010R1009\&from=EN

[5] BRASIL. Ministério das Cidades. Conselho Nacional de Trânsito. Resolução no 201, de 25 de agosto de 2006. Estabelece os limites de peso e dimensões para veículos que transitem por vias terrestres e dá outras providências. Disponível em http://www.denatran.gov.br/download/Resolucoes/RESOLUCAO_210.rtf.

[6] BOSCH, Robert. Manual de tecnologia automotiva/Robert Bosch. São Paulo: Edgard Blücher, 2005. P764, 765 e 787 